\title{
The "Greening" of Natural Stone Buildings: Quartz Sandstone Performance as a Secondary Indicator of Climate Change in the British Isles?
}

\author{
Stephen McCabe*, Bernard Smith, Catherine Adamson, Donal Mullan, Daniel McAllister \\ School of Geography, Archaeology and Palaeoecology, Queen's University Belfast, Belfast, Northern Ireland \\ E-mail: "stephen.mccabe@qub.ac.uk
}

Received July 24, 2011; revised August 28, 2011; accepted September 10, 2011

\begin{abstract}
A number of recent studies have explored the impact of climate change on natural building stones. Because of its sensitivity to change, sandstone can be seen as having a predictable, recognizable and sustained response to changes in system inputs that control performance-most crucially for the UK and Ireland, how it responds to an increased moisture input. There has been a widespread biological "greening" of sandstone buildings in response to these periods of wetness during autumn, winter and spring months. Furthermore, there is a wealth of literature detailing the response of sandstone in a variety of environments where sandstone response is representative of the environment in which it has been placed. This paper suggests that the response of sandstone to trends towards wetter winter conditions is predictable to the extent that it may have potential to be a secondary indicator of climatic change-that is, a system that alters in response to fluctuations in environmental conditions in a sustained way. It is hoped that the paper may stimulate discussion as to what other possible indicators of climatic change remain unacknowledged.
\end{abstract}

Keywords: Climate Change, Sandstone, Weathering, Greening

\section{Introduction}

The perpetual predicament of climate change scientists is how to convince the public-and policy makers-of the validity of their predictions. To do this ideally requires unambiguous evidence drawn from reliable climate-related indicators. The difficulty is, however, that such secondary indicators involve varying degrees of ambiguity relating to system responses that can be influenced by a wide range of factors. This paper suggests that one previously unconsidered, relatively unambiguous, secondary indicator of climatic change is seen in the "greening" of our natural stone buildings (Figure 1). It is hoped that the paper may stimulate discussion as to what other possible indicators of climatic change or environmental change remain unacknowledged.

Several recent studies have sought to investigate how sandstone structures respond to climate change (for example, [1-5]). With changes in environment, the factors that control the performance of sandstone in buildings and monuments also change. These interrelationships are especially apparent in the NW British Isles, where there is a perceptible observed trend towards wetter conditions especially in winter months. Observed data from two of the longest and best quality rainfall records representing the west (Lough Navar Forest) and the east (Helen's Bay) of NI help illustrate this trend (Figure 2). Based on analysis of five-year moving averages of winter precipitation from the early 1960s to near the end of the last decade, mean increases in excess of $100 \mathrm{~mm}$ can be observed at Lough Navar Forest (ca. 28\%), with smaller but still considerable increases of $45 \mathrm{~mm}$ (ca. 18\%) at Helen's Bay. Data even show that summer rainfall has been increasing in recent decades, with Lough Navar Forest and Helen's Bay displaying a $14 \%$ and $18 \%$ increase respectively. Natural stone buildings in the NW British Isles appear to have responded to this trend by biological "greening" (Figure 1), principally from algal growth. We hypothesise that this greening is likely to be a response to wetter exposure conditions, possibly in combination at some locations with reduced atmospheric sulphur dioxide and an increase in atmospheric nitrogen from vehicular pollution [3]. This paper proposes that the sensitivity of quartz sandstone to environmental change is sufficiently 


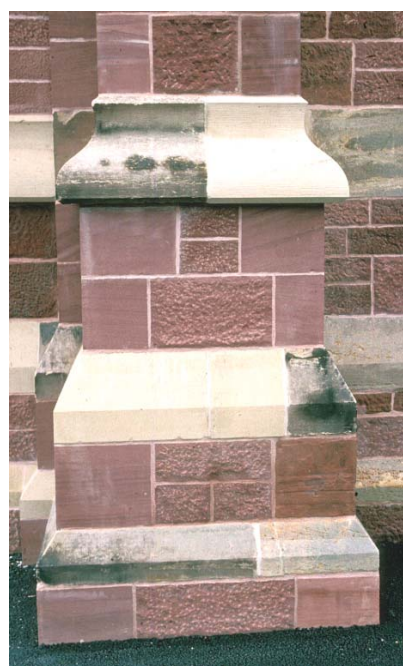

(a)

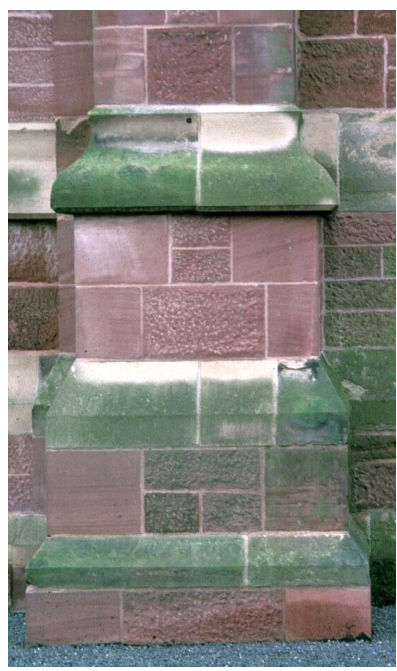

(b)

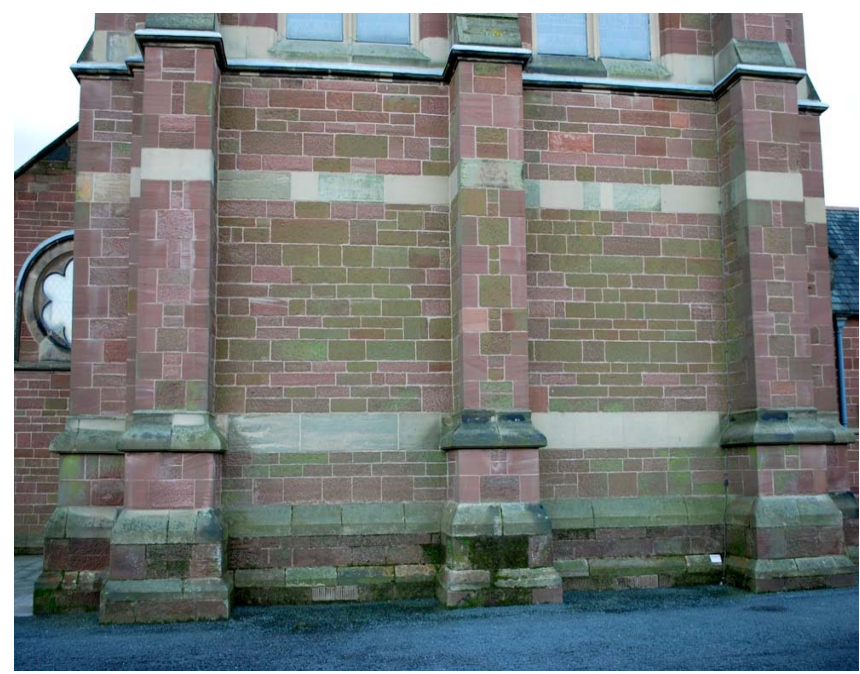

(c)

Figure 1. Algal "greening" of St Mark's church in Belfast; (a) Cleaned stone buttress, May 1999; (b) the same buttress, October 2001; (c) North-facing façade, January 2011.

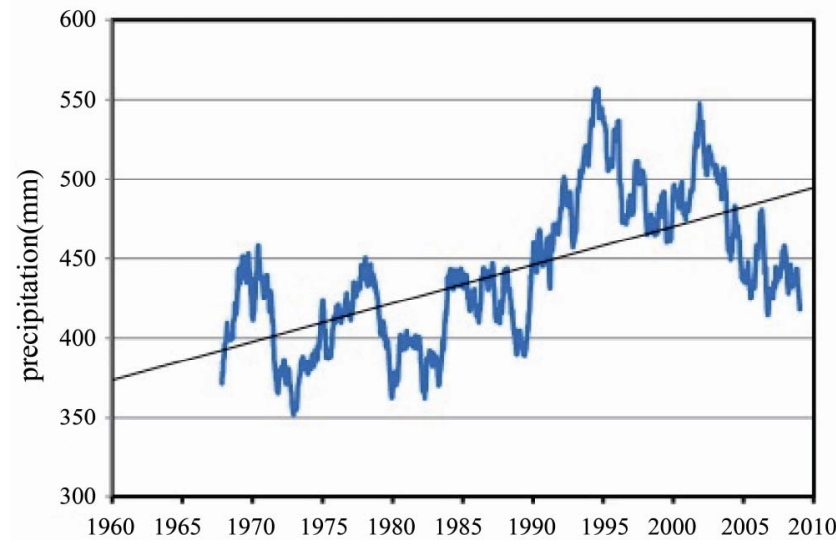

(a)

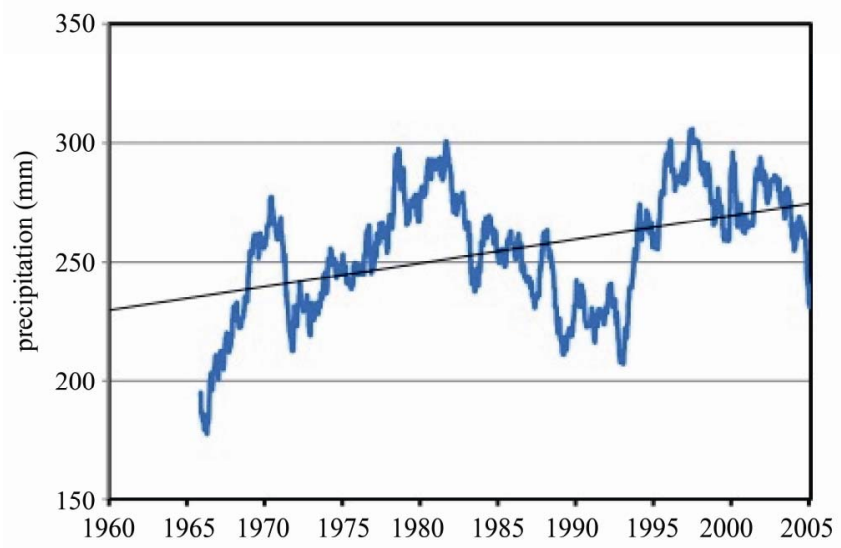

(c)

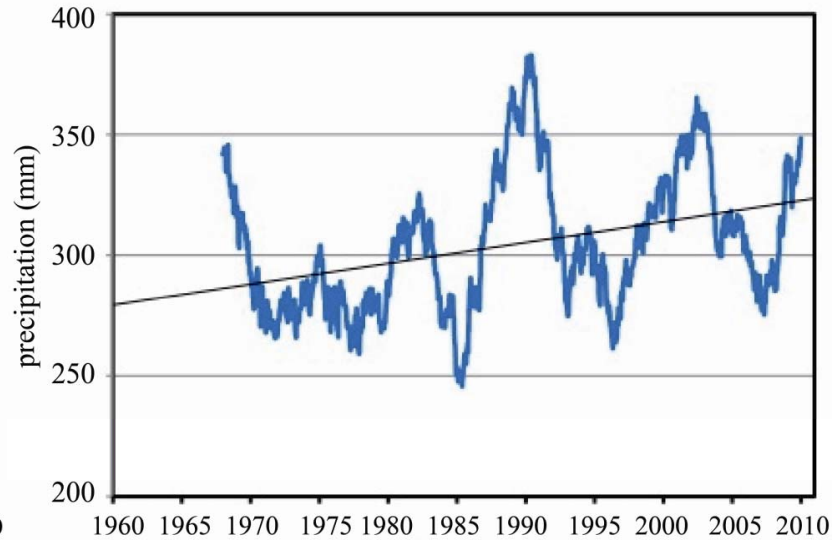

(b)

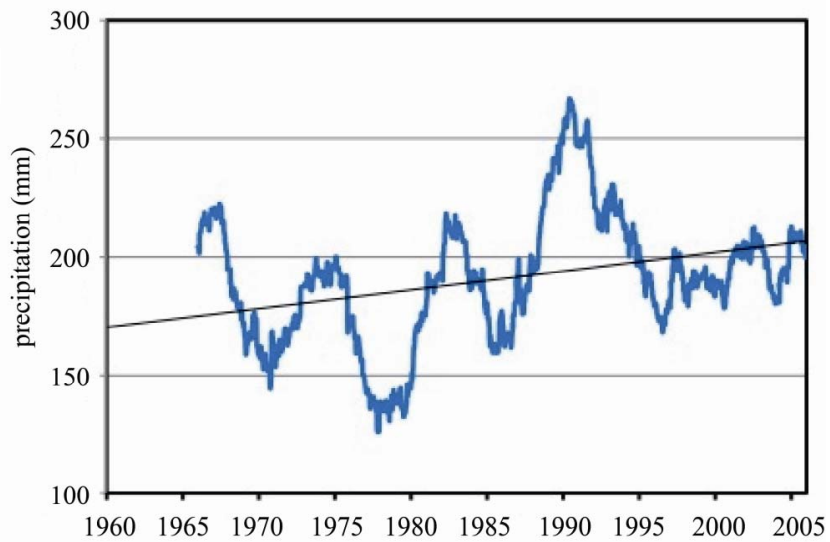

(d)

Figure 2. (a) Observed record of winter rainfall at Lough Navar in the west of NI (Co. Fermanagh), 1963-2009; (b) Observed record of summer rainfall at Lough Navar in the west of NI (Co. Fermanagh), 1963-2009; (c) Observed record of winter rainfall at Helen's Bay in the east of NI (Co. Down), 1961-2005; (d) Observed record of summer rainfall at Helen's Bay in the east of NI (Co. Down), 1961-2005. Graphs are based on five-year moving averages. NB differences in Y-axis scales. 
predictable to permit its use as a secondary indicator of climate change. Previously any such potential may have been locally masked by mineral soiling and colour change of stone in response to atmospheric pollutionthe reduction in atmospheric pollution in many cities has opened the way for natural stone to show its sensitivity to wider climatic change. It should be noted that the response to climate change in this region has been largely biological in nature, but that sandstone is a particularly suitable and sensitive host to the colonizing organisms [6], because its mineral and pore characteristics are especially bioreceptive. Bioreceptivity describes "the aptitude of a material to be colonized by one or more groups of living organisms without necessarily undergoing any biodeterioration. The word "colonize" is important since it implies that there is an ecological relationship between the material and the colonizing organisms" [7, p. 216]. Primarily, texture or roughness gives pioneering microorganisms or their spores cavities to settle in, making it less likely for them to be removed from the surface by wind or rain. A more connected porous substrate will also retain more water, again enhancing microbial growth and enabling a wider range of different organisms to inhabit it. Sandstone ably fills criteria for bioreceptivity, with its open-texture, pore connectivity and potential mineral interactions with colonizers.

The "greening" of natural building stones has signifycant implications for biological, physical and chemical decay processes-these are dealt with in detail in the literature, most recently by [2] and [8]. In particular it is proposed that algal biofilms can aid moisture retention and further facilitate moisture and dissolved salt penetration to depth in building stones. Thus, whilst the outer surface of stone may continue to experience frequent wetting and drying associated with individual precipitation events, the latter is less likely to be complete and the interiors of building blocks may only experience wetting/drying in response to seasonal cycling.

\section{Indicators of Climatic and Environmental Change}

$[9,10]$ identify a variety of primary and secondary indicators of climate change. Indicators are systems (or organisms) that alter in response to fluctuations in environmental conditions [10]. Primary indicators are those directly related to the climate system-trends in air temperatures, precipitation, cloud cover and macro-scale circulation indices. Secondary indicators "comprise phenolmena that are likely to show responses to changes in primary climatic components" [9, p. 26]. These include shifts in agriculture, the behavior of butterflies, bats, birds, fish stocks, tree growth and plant distribution as well as human considerations like health, tourism and energy consumption. Weathering studies have been concerned for a long time with investigating how sandstone/environment systems respond to the primary climatic components of temperature and moisture input, and to how sensitive stone is to changes in those inputs-this makes sandstone a prime candidate for being a secondary indicator of change.

[11] and subsequently [9], have set out a number of criteria for climate change indicators. Thus, an indicator should:

Provide a representative picture of environmental conditions;

Show trends over time and be easily interpreted;

Be responsive to change;

Be comparable internationally;

Be national in scope or applicable to regional environmental issues;

Have a reference against which comparisons can be made;

Be well founded in technical and scientific terms;

Be based on international standards;

Be linked to forecasting and information models;

Be of high quality, well documented and updated regularly;

Be readily available at a reasonable cost.

\section{The Suitability of Sandstone Performance as an Indicator}

Potentially, sandstone fulfils all of these criteria. However, as [9] note, "selecting indicators which fulfill all these criteria, presents great difficulties" and that we should "select indicators that fit these criteria as far as possible" [9, p. 4]. Thus, while some of the criteria are only fulfilled potentially (depending on continued monitoring and development of records-ongoing), any shortcomings at this stage should not detract from that potential and the fact that sandstone performance is particularly strong in some of these areas-i.e. providing a representative picture of environmental conditions, showing trends over time, and being responsive to change.

Sandstone is widely used in the UK and Europe as a building material (both historically and in new build), with much research having been undertaken on understanding the response of sandstone to varied environments around the globe [12-14, 15-17]. Two of the primary indicators of climate change (noted above, [9]) temperature and moisture, are the key controls on the performance of sandstone. Thus, if these change, we would expect to see the change reflected in sandstone performance. [18], who investigated the response of three different stone types across a range of environments, have 
stated, "all three stone materials show a fast response to environmental impact, to pollution as well as to meteorological factors (humidity/rain, frost/thaw)" [18, p. 109] (emphasis added). As sandstones are already found in buildings and monuments they are readily available, and any cost in using them as environmental indicators will be in the simple ongoing monitoring of the stone. However, the need for the standardizing of condition assessment (monitoring method) is crucial, and has been highlighted by [19] in their proposed staging system condition assessment scheme.

\subsection{Sandstone as Representative of Environmental Conditions}

Stone decay studies have long used stone exposure trials in an attempt to understand how stone may perform in a given environment. Stone exposure trials provide a sensitive indication of the environment into which they are placed [20-22], [18]—-many speaking of sandstone as a sensor material.

For example, a 6-year study (1993-1999) [23] was carried out using a relatively "inert" stone (in the sense that it has a lack of secondary, easily weatherable, minerals)Dunhouse Sandstone-to investigate surface change and decay on sandstone in the polluted urban environment of Belfast city centre. The response of the stone was rapidsurface change was evident after only 3 months of exposure. After 6 years of exposure, a rich picture of the depositional environment was available-showing deposits of fly ash, gypsum, organic material and other adhering debris, as well as dissolution features on the stone (representing a relatively aggressive urban weathering environment).

While many studies have been largely concerned with stone representativeness of environmental conditions in urban areas, other studies have shown that the performance of sandstones over long periods of time in exposed maritime and rural environments also show similar patterns [17,24]— "facades situated in exposed maritime environments that allow periodic wetting and drying of stonework show very similar patterns of decay, with recurring decay forms" [25, p. 171]. This strongly indicates that, over long periods of time, sandstone responds in a predictable and sustained way to environmental exposure conditions.

\subsection{Sandstone Responsiveness/Sensitivity to Change-Staggering the Exposure of Fresh Stone}

A common fallacy concerning stone is that it is immutable-not subject to change, or that, if change does occur, it is very slow [26]. Again, exposure trials in stone decay studies have shown this assumption to be wrong. Surface change can be very rapid in response to environment (giving a representative picture, described above), and can also reflect environmental change. The reduction in local atmospheric pollution in recent times has paved the way for the sandstone to reflect wider climatic influences-especially increased in winter wetness. More recent exposure trials detailed by [1] demonstrate this ability to identify climatic change. This work, showed that exposure trials for sandstones in Belfast running from April 1999 to March 2001 were markedly different to those carried out in the early 1990s (described above, [23]). Results showed that all of the sandstones had responded to exposure by "greening". Algal and fungal colonization were both evident, creating an adhesive surface that was effective in binding other particulate matter. As mentioned, these results after 3 years of exposure stand in marked contrast to previous exposure trails in Belfast in the early 1990s, in which biological colonization was not present to the same extent [1]. Thus, the exposure of fresh sandstone samples, staggered over a period of time, is able to identify this kind of progressive change.

[5] has re-enforced this temporal change in sandstone performance with a spatial study comparing precipitation and biological greening on sandstone monuments across NI. They demonstrated that biological soiling on these monuments largely followed a west/east precipitation gradient, where the Atlantic signal coming from the west of the country enhances precipitation [27]. Results show-ed higher levels of biological soiling evident in the wetter North-West of Northern Ireland where annual precipitation is higher in response to the strong Atlantic signal as compared to lower levels of biological soiling evident in the more rain-sheltered South-East. Thus, the climatic signal is picked up and displayed in the sandstone monuments and their level of biological soiling-Figure 3 shows a map of Northern Ireland with rainfall and monuments exhibiting biological soiling overlaid. As part of the overall study, Adamson exposed Blaxter Sandstone samples at sites around NI-after a period of only 13 months (August 2009-November 2010), algae had grown on north-facing samples on the west of NI (Derrygonnelly, Co. Fermanagh), while north-facing samples in the east (Belfast) showed less colonization [3,5]-see Figures 4(a)-(b). This again demonstrates the potential of the sandstone soiling to discriminate between environments based on wetness trends.

\section{Limitations and Ways Forward}

The authors acknowledge that there are clear limitations to the use of quartz building sandstone as an indicator of 


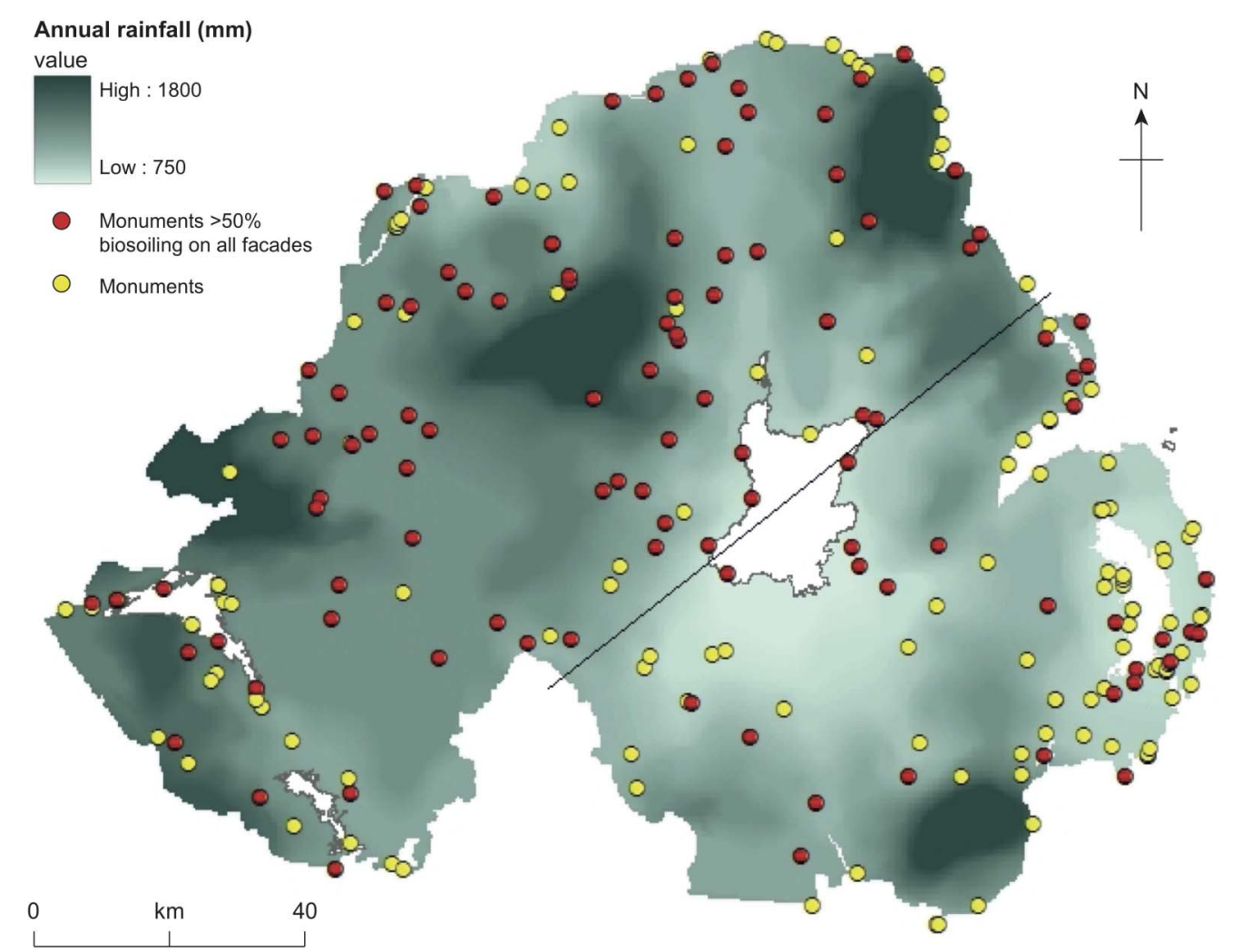

Figure 3. Map of rainfall across NI, with monuments showing $<\mathbf{5 0 \%}$ biological soiling on all façades as red dots. The black line highlights the distinction between stone response in the wetter NW and drier SE of the country.

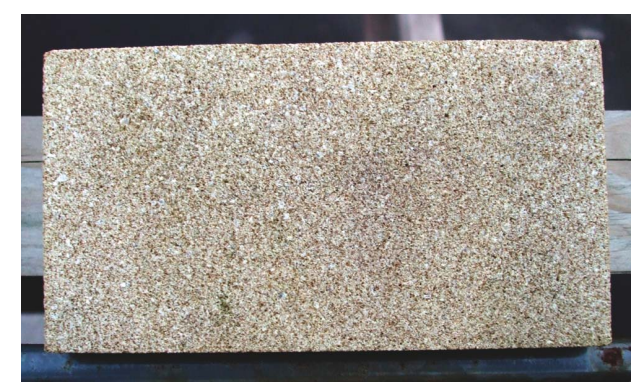

(a)

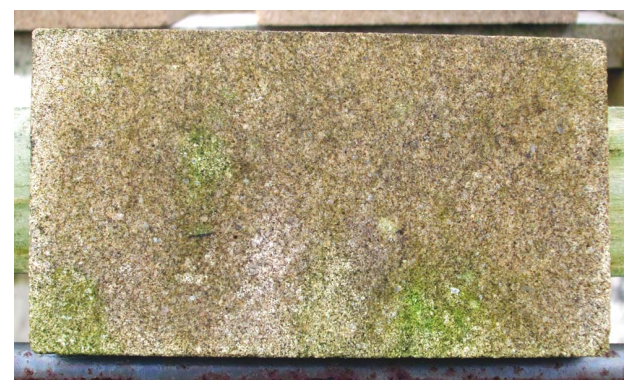

(b)

Figure 4. (a) shows a relatively unsoiled Blaxter Sandstone sample exposed in Belfast (August 2009-December 2010), (b) shows a Blaxter Sandstone sample exposed in the wet west of NI, Omagh over the same period. Both samples were north facing.

climatic change. However, we offer these ideas with the intention of stimulating discussion on what other possible indicators have remained unrecognized. We stress that all the results in this paper are observed, rather than projected-i.e. we are working on the basis of changes that have and are continuing to take place (both in terms of climatic change and stone response).

$[9$, p. xi] discuss the "confounding effect of localized factors", i.e., do site-specific factors override the effects of the general climate? This is certainly an issue that needs some addressing, however, studies have shown that West/North facing aspects tend to stay wet for longer periods (i.e. trends do emerge that reflect the wider environment). So, being aware of this and, for example, making sure the elevation is exposed and not over-looked by adjacent vegetation, as well as standardizing which aspect of a structure is monitored can overcome these difficulties. One problem with secondary indicators of climate change in general noted by $[9$, p. 4$]$ is that "studies are normally short term, in a relatively local area and involve a small 
number of species, thus missing out on the processes that are taking place over many years". The natural stone database for Northern Ireland, undertaken by Queen's University Belfast and Consarc Design Group architects (www.stonedatabase.com), addresses some of these issues by covering all of NI and looking at over 800 sandstone buildings and monuments, giving an opportunity to develop and make meaningful statements about longterm change. The stone database breaks each structure down into their 4 different aspects, each monitored separately. The way forward, in terms of viewing sandstone performance as a secondary indicator of climatic change, is clearly for continued monitoring to be carried out, both with the staggered exposure of fresh sandstone, and development of the natural stone database to build a clearer picture of stone response over time across NI and for over 800 structures. Perhaps the validity of quartz building sandstone as a secondary indicator of climate change could be more established by building a database of stone response globally in different types of environment-from arid to tropical. In this case, it would be expected that the response of stone surface to, for example, moisture supply would again reflect the environment in which they are situated.

\section{Acknowledgements}

This work was funded by EPSRC grant EP/G01051X/1, along with an EPSRC-funded Impact Award. Thanks go to Gill Alexander (QUB cartography) for the preparation of figures.

\section{References}

[1] B. J. Smith, P. A. Warke and J. M. Curran, "Implications of Climate Change and Increased 'Time-of-Wetness' for the Soiling and Decay of Sandstone Structures in Belfast, Northern Ireland," In: R. Prikryl, Ed., Dimension Stone, Taylor \& Francis, London, 2004, pp. 9-14.

[2] H. A. Viles, "Implications of Future Climate Change for Stone Deterioration," In: S. Seigesmund, T. Weiss and A. Volbrecht, Eds., Natural Stone, Weathering Phenomenon, Conservation Strategies and Case Studies, Geological Society, London, Special Publications, Vol. 205, 2002, pp. 407-418.

[3] B. J. Smith, S. McCabe, D. McAllister, C. Adamson, H. A. Viles and J. M. Curran, "A Commentary on Climate Change, Stone Decay Dynamics and the 'Greening' of Natural Stone Buildings: New Perspectives on 'Deep Wetting,," Environmental Earth Sciences, Vol. 63, No. 7-8, 2011, pp. 1691-1700. doi:10.1007/s12665-010-0766-1

[4] S. McCabe, B. J. Smith, J. McAlister, H. A. Viles, J. M. Curran and T. Crawford, "Climate Change and Wet Winters: Testing the Diffusion of Soluble Salts in Building Stone under Saturated Conditions," XIX Congress of the
Carpathian and Balkan Geological Association, Vol. 100, 2010, pp. 399-405.

[5] C. S. Adamson, S. McCabe, D. McAllister, B. J. Smith and P. A. Warke, "Mapping the Spatial Distribution of Precipitation, Biological Soiling and Decay on Monuments in Northern Ireland: Towards Understanding LongTerm Stone Response to Moisture," XIX Congress of the Carpathian Balkan Geological Association, Thessaloniki, 2010, Vol. 99, pp. 183-190.

[6] A. Gorbushina, "Life on the Rocks," Environmental Microbiology, Vol. 9, No. 7, 2007, pp. 1613-1631. doi:10.1111/j.1462-2920.2007.01301.x

[7] O. Guillitte, "Bioreceptivity: A New Concept for Building Ecology Studies," The Science of the Total Environment, Vol. 167, No. 1-3, 1995, pp. 215-220. doi:10.1016/0048-9697(95)04582-L

[8] N. Cutler and H. Viles, "Eukaryotic Microorganisms and Stone Biodeterioration," Geomicrobiology Journal, Vol. 27, No. 6, pp. 630-646. doi:10.1080/01490451003702933

[9] J. Sweeney, A. Donnelly, L. McElwain and M. Jones, "Climate Change Indicators for Ireland," Final Report, Environmental Protection Agency, Dublin, 2002.

[10] A. Donnelley, M. B. Jones and J. Sweeney, "A Review of Indicators of Climate Change for Use in Ireland," International Journal of Biometerology, Vol. 49, 2004, pp. $1-12$.

[11] OECD, "OECD Core Set of Indicators for Environmental Performance Reviews," Organization for Economic Cooperation and Development, Paris, 1993.

[12] B. Smith, B. Whalley and V. Fassina, "Elusive Solution to Monumental Decay," New Scientist, 1988, pp. 49-53.

[13] R. U. Cooke, "Laboratory Simulation of Salt Weathering Processes in Arid Environments," Earth Surface Processes and Landforms, Vol. 4, 1979, pp. 347-359.

[14] K. Hall, C. E. Thorn, N. Matsuoka and A. Prick, "Weathering in Cold Regions: Some Thoughts and Perspectives," Progress in Physical Geography, Vol. 26, 2002, pp. 577-603. doi:10.1191/0309133302pp353ra

[15] B. J. Smith, A. V. Turkington, P. A. Warke, P. A. M. Basheer, J. J. McAlister, J. Meneely and J. M. Curran, "Modelling the Rapid Retreat of Building Sandstones: A Case Study from a Polluted Maritime Environment," In: S. Seigesmund, T. Weiss and A. Vollbrecht, Eds., Natural Stone, Weathering Phenomenon, Conservation Strategies and Case Studies, Geological Society, London, Special Publications, Vol. 205, 2002, pp. 347-362.

[16] S. McCabe, B. J. Smith and P. A. Warke, "A Legacy of Mistreatment: Conceptualizing the Decay of Medieval Sandstones in NE Ireland," In: R. Prikryl and A. Torok, Eds., Natural Stone Resources for Historical Monuments, Geological Society, London, Special Publications, Vol. 333, 2010, pp. 87-100.

[17] S. McCabe and B. J. Smith, "Understanding the Long-Term Survival of Sandstone in Medieval Ecclesiastical Structures: Northern Ireland and Western Scotland," In: M. Dan Bostenaru, R. Prikryl and A. Torok, Eds., Materials, Technologies and Practice in Historic Heri- 
tage Structures, Springer, Heidelburg, 2010, pp. 107-136. doi:10.1007/978-90-481-2684-2 7

[18] T. Bidner, P. W. Mirwald, A. Recheis and S. Bruggerhoff, "Stone as a Sensor Material for Weathering," In: R. Prikryl and H. A. Viles, Eds., Understanding and Managing Stone Decay, The Karolinum Press, Prague, 2002, pp. 97-111.

[19] P. A. Warke, J. M. Curran, A. V. Turkington and B. J. Smith, "Condition Assessment for Building Stone Conservation: A Staging System Approach," Building and Environment, Vol. 38, No. 9-10, 2003, pp. 1113-1123. doi:10.1016/S0360-1323(03)00085-4

[20] B. J. Smith, W. B. Whalley, J. Wright and V. Fassina, "Short-Term Modification of Limestone Test Samples: Examples from Venice and the Surrounding Area," In: V. Fassina, H. Ott and F. Zezza, Eds., III International Symposium on the Conservation of Monuments in the Mediterranean Basin, 1994, pp. 217-226.

[21] S. Bruggerhoff, L. Georg and S. Jurgen, "Environmental Monitoring with Natural Stone Sensors," In: J. Rieder, Ed., 8th International Congress on Deterioration and Conservation of Stone, Berlin, 1996, pp. 861-869.

[22] P. W. Mirwald, S. Bruggerhoff and R. Fimmel, "Baumberg Calcareous Sandstone and Obernkirchener Sandstone, Natural Sensor Materials for Environmental Moni-
toring-Results of a Field Exposure," 8th International Congress on Deterioration and Conservation of Stone, Berlin, 1996, pp. 871-877.

[23] A. V. Turkington, E. Martin, H. A. Viles and B. J. Smith, "Surface Change and Decay of Sandstone Samples Exposed to a Polluted Urban Atmosphere over a Six-Year Period: Belfast, Northern Ireland," Building and Environment, Vol. 38, No. 9-10, 2003, pp. 1205-1216. doi:10.1016/S0360-1323(03)00077-5

[24] A. V. Turkington, "The Durability of Sandstone in Salt-Rich Environments," $\mathrm{PhD}$ Dissertation, Queen's University Belfast, Belfast, 1999.

[25] S. McCabe, "The Impact of Complex Stress Histories on the Decay of Historic Sandstone," PhD Dissertation, Queen's University Belfast, Belfast, 2007.

[26] B. J. Smith, M. Gomez-Heras and S. McCabe, "Understanding the Decay of Stone-Built Cultural Heritage," Progress in Physical Geography, Vol. 32, 2008, pp. 439-461. doi:10.1177/0309133308098119

[27] T. Crawford, N. L. Betts and D. Favis-Mortlock, "GCM Grid-Box Choice and Predictor Selection Associated with Statistical Downscaling of Daily Precipitation over Northern Ireland," Climate Research, Vol. 34, No. 2, 2007, pp. 145-160. doi:10.3354/cr034145 